\title{
Deafness-craniofacial syndrome
}

\author{
INSERM
}

\section{Source}

INSERM. (1999). Orphanet: an online rare disease and orphan drug data base. Deafnesscraniofacial syndrome. ORPHA:3241

Deafness-craniofacial syndrome is characterised by the association of congenital hearing loss and facial dysmorphism (facial asymmetry, a broad nasal root and small nasal alae). It has been described in two members (father and daughter) of one Jewish family. Temporal alopecia was also noted. Transmission appeared to be autosomal dominant. 